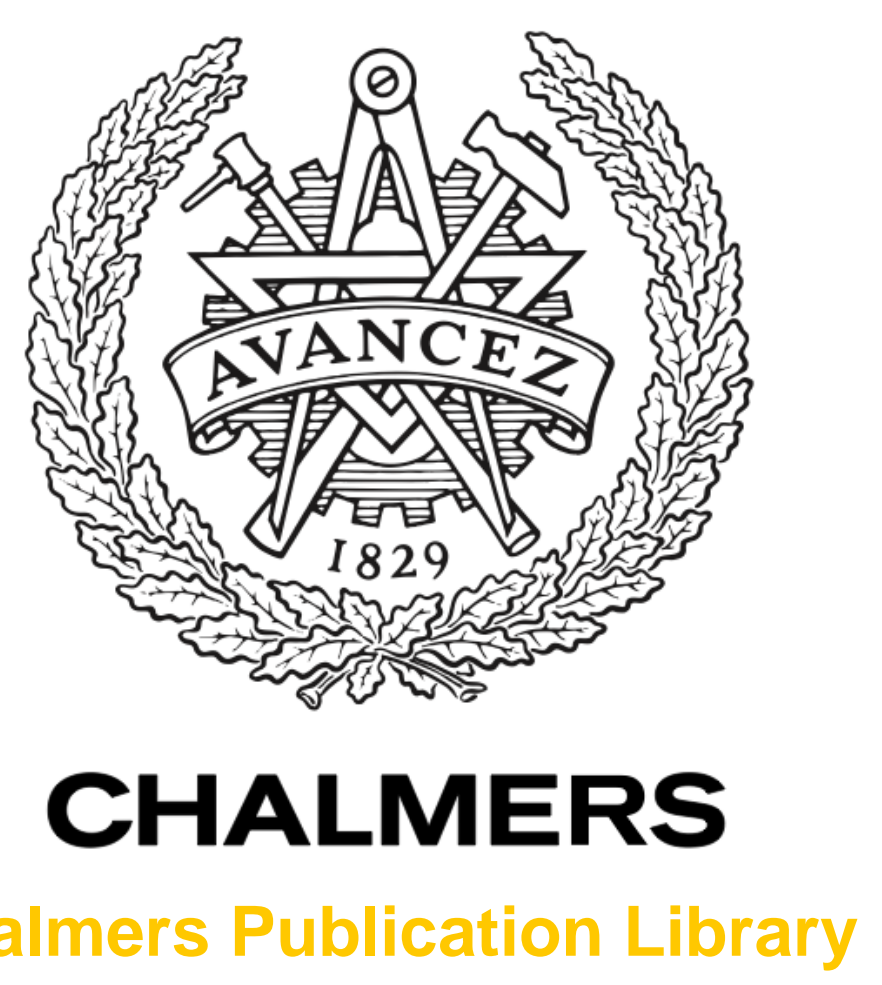

Chalmers Publication Library

\title{
Measurements of Gas Concentrations in a Fluidized Bed Combustor Using Laser- Induced Photoacoustic Spectroscopy and Zirconia Cell Probes
}

This document has been downloaded from Chalmers Publication Library (CPL). It is the author's version of a work that was accepted for publication in:

Combustion and Flame (ISSN: 0010-2180)

Citation for the published paper:

Stenberg, J. ; Åmand, L. ; Hernberg, R. et al. (1998) "Measurements of Gas Concentrations in a Fluidized Bed Combustor Using Laser-Induced Photoacoustic Spectroscopy and

Zirconia Cell Probes". Combustion and Flame, vol. 113(4), pp. 477-486.

http://dx.doi.org/10.1016/S0010-2180(97)00245-9

Downloaded from: http://publications.lib.chalmers.se/publication/5225

Notice: Changes introduced as a result of publishing processes such as copy-editing and formatting may not be reflected in this document. For a definitive version of this work, please refer to the published source. Please note that access to the published version might require a subscription. 


\title{
Measurements of Gas Concentrations in a Fluidized Bed Combustor Using Laser-Induced Photoacoustic Spectroscopy and Zirconia Cell Probes
}

\author{
J. STENBERG,* L.-E. ÅMAND, R. HERNBERG, and B. LECKNER \\ Tampere University of Technology, Plasma Technology Laboratory, P.O. Box 692, FIN-33101, Tampere, Finland \\ (J. S., R. H.) and Chalmers University of Technology, Department of Energy Conversion, Hörsalsvägen 7 , \\ SE-41296, Gothenburg, Sweden (L.-E. A., B. L.)
}

\begin{abstract}
The dynamic combustion behavior of a circulating, fluidized bed boiler (CFB) was studied using two high-speed gas analysis systems during the combustion of coal, peat, and wood chips. Time-resolved concentrations of $\mathrm{SO}_{2}$ and NO were measured by laser-induced photoacoustic spectroscopy (LIPS). A zirconia-cell based probe ( $\lambda$-probe), synchronized with the LIPS probe, measured fluctuations between reducing and oxidizing conditions. The two probes were positioned in the same measurement volume on the centerline of the CFB combustion chamber. The purpose of the work was to investigate the behavior of the LIPS in a combustion chamber containing reacting gases in order to extend the previous $\lambda$-probe measurements to other gas components. Correlations between oxidizing and reducing conditions and gas species concentrations in three locations in the combustion chamber are presented. The best correlations were found in the upper part of the CFB combustion chamber. In some cases the correlation between reducing conditions and the LIPS signal was caused by unburnt hydrocarbons. Average values of $[\mathrm{NO}]$ and $\left[\mathrm{SO}_{2}\right]$ obtained by the LIPS system were compared with the results from a sampling probe connected to on-line analyzers. The measurements of [NO] and $\left[\mathrm{SO}_{2}\right]$ were disturbed by interfering gases during reducing conditions. During a sufficiently long time of oxidizing conditions, however, reasonable agreement was obtained between LIPS measurements of [NO] and $\left[\mathrm{SO}_{2}\right]$ and those of the on-line analyzers. On some occasions (low $\mathrm{SO}_{2}$ concentration) the concentration of the $\mathrm{OH}$ radical was also measured. (C) 1998 by The Combustion Institute
\end{abstract}

\section{NOMENCLATURE}

$n \quad$ number density $\left(1 / \mathrm{m}^{3}\right)$

$r \quad$ distance $(\mathrm{m})$

$r_{0} \quad$ laser beam radius $(\mathrm{m})$

$C \quad$ molar specific heat $[\mathrm{J} /(\mathrm{mol} \mathrm{K})]$

$D$ diameter (m)

E energy (J)

$F \quad$ Faraday constant [96487 (A s)/mol]

$R \quad$ gas constant $[8.315 \mathrm{~J} /(\mathrm{mol} \mathrm{K})]$

$P \quad$ pressure $(\mathrm{Pa})$

$T_{1} \quad$ temperature in the combustion chamber (K)

$\mathrm{T}_{2} \quad$ room temperature (K)

$Z$ acoustic impedance $\left[\mathrm{kg} /\left(\mathrm{m}^{2} \mathrm{~s}\right)\right]$

$\Delta P_{O} \quad$ acoustic signal amplitude inside the laser beam $(\mathrm{Pa})$

$\Delta P_{r} \quad$ acoustic signal amplitude in the microphone $(\mathrm{Pa})$

$\eta_{C} \quad$ efficiency by which absorbed laser

*Corresponding author: Tampere University of Technology, Dept. of Physics, P.O. Box 692, FIN-33101 Tampere, Finland.

COMBUSTION AND FLAME 113:477-486 (1998)

(C) 1998 by The Combustion Institute

Published by Elsevier Science Inc. energy is converted to thermal energy

(1)

$\sigma \quad$ cross section $\left(\mathrm{m}^{2}\right)$

$\begin{array}{ll}\text { Subscripts } \\ L & \text { laser pulse } \\ \mathrm{O}_{2} & \text { oxygen molecule } \\ V & \text { constant volume } \\ a & \text { absorption } \\ \text { meas } & \text { measured } \\ \text { ref } & \text { reference } \\ s & \text { species } s\end{array}$

\section{INTRODUCTION}

For a better understanding of combustion in a fluidized bed combustor there is a need to measure the time variations of the gas concentrations in various parts of the combustor. Several methods used in flames cannot be applied to fluidized beds, because of the high concentration of particles. Until now only changes between oxidizing and reducing conditions have been recorded in fluidized bed combustors with 


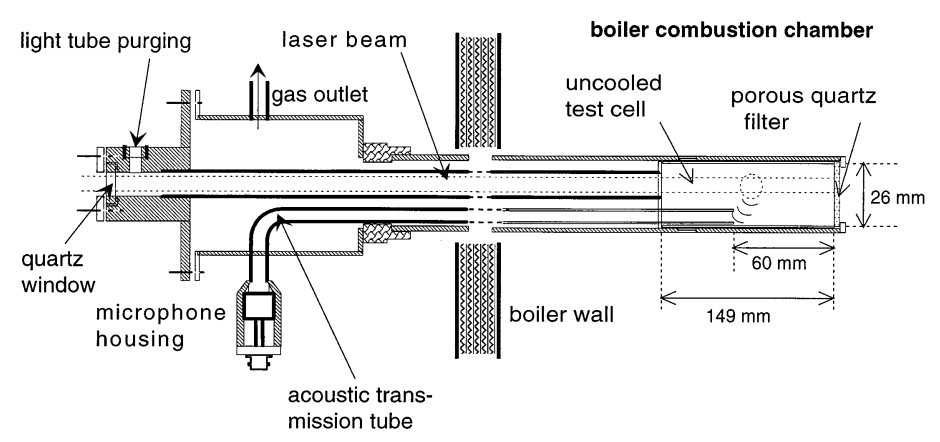

Fig. 1. The design of the LIPS probe.

zirconia-cell probes [1-3]. Under normal operating conditions such changes take place on a time-scale of $\sim 1 \mathrm{~s}$ in a bubbling bed, as well as in the bottom part of a circulating fluidized bed (CFB) combustor, whereas higher up in a CFB furnace the variations are less frequent [2]. The operating strategy of the boiler has a large impact on these conditions. To explore the possibility of fast measurements of more gaseous components, the present work evaluates a laser-induced photoacoustic spectroscopy (LIPS) probe in a CFB furnace. This technique has been developed and used in laboratory combustors $[4,5]$, but there is no experience of in situ measurements in a reacting medium and the method has not been tested in an industrial environment. The LIPS probe utilizes ultraviolet (UV) and visible wavelengths to detect gaseous species during combustion. This wavelength range has some advantages over that of infrared (IR) spectroscopy for the analysis of flue gases. Major components, like $\mathrm{H}_{2} \mathrm{O}, \mathrm{CO}$, $\mathrm{CO}_{2}$, and $\mathrm{CH}_{4}$, which affect spectrally the measurement of other gaseous species in the IR, do not absorb light in the UV or visible wavelengths. In reacting gases, however, a variety of gases is present. These include larger hydrocarbon molecules, which absorb light in the UV. Furthermore, the absorption spectra of molecules at combustion temperatures are wider than those at room temperature, due to the population of higher rotational and vibrational excited states. Thus, absorption may appear at wavelengths, where the absorption at room temperature is very weak and difficulties in interpreting the LIPS signal may arise.

The aims of the present work are: (1) to find methods for characterizing the fluctuation of the gas concentrations in a fluidized bed combustor; (2) to test the usefulness of the LIPS probe for measuring gas concentration in the presence of reacting gases; and (3) to verify the applicability of the LIPS method in an industrial environment. For this purpose, time-resolved concentrations of $\mathrm{SO}_{2}$ and $\mathrm{NO}$ were measured by the LIPS probe. Simultaneously, measurements were carried out with a $\lambda$-probe and with conventional, local, time-averaging gas analysis equipment.

\section{THEORY}

\section{The LIPS Probe}

The theory of LIPS gas analysis has been presented elsewhere $[4,5]$ and only a short description of the theory of pulsed photoacoustic (PA) technique is given here. The design of the LIPS probe used in this work is shown in Fig. 1. Pulsed laser light tuned in resonance with an absorption wavelength of a gas species $s$ is directed to the hot measurement cell. Under the conditions prevailing in combustion gases the absorbed laser energy is partially converted to heat in a few microseconds [6]. As the temperature in the gas sample along the laser beam increases rapidly, a cylindrical acoustic wave is generated with an amplitude:

$\Delta P_{0}=E_{L} n_{s} \sigma_{a s} \eta_{C} \frac{R}{\pi r_{0}^{2} C_{V}}$

The gas's concentration $n_{s}$ can be obtained from the measured $\Delta P_{O}$ if the other parameters in Eq. 1 are known. Due to the abundance of both $\mathrm{H}_{2} \mathrm{O}$ and $\mathrm{CO}_{2}$, the quenching efficiency of the 
excited electronic state $\eta_{C}$ is in the narrow range of $0.98-1.00$ for most molecules under study. This is in contrast to LIFS measurements, where the signal depends on $\left(1-\eta_{C}\right)$, resulting in a large uncertainty if not compensated for. Another enhancement of a LIPS signal comes from the temperature difference between the hot test cell (typically at $850^{\circ} \mathrm{C}$ ) and the detecting microphone (at room temperature). While traveling from the hot test cell to the cold microphone, the acoustic pulse experiences an increasing acoustic impedance $Z$, because $Z$ is proportional to $T^{1 / 2}$. The acoustic signal is amplified by a factor

$\frac{2}{1+Z_{1} / Z_{2}} \equiv \frac{2}{1+\sqrt{T_{2} / T_{1}}}$

which is 1.31 for $T_{2}=293 \mathrm{~K}$ and $T_{1}=1123 \mathrm{~K}$. The amplitude $\Delta P_{0}$ in Eq. 1 is that of the acoustic signal in the heated cylindrical volume of the test cell. For practical reasons the amplitude of the acoustic pulse cannot be measured in the location of its generation inside the laser beam. Instead, the acoustic signal is sensed by an acoustic transmission tube located at a distance $r$ from the center of the laser beam where the amplitude of the acoustic wave is

$\Delta P_{r}=\Delta P_{0} \sqrt{r_{0} / r}$

The unwanted, laser-induced, acoustic signals not related to $n_{s}$ are separated using the principles of photoacoustic ranging and detection (PADAR) [5, 7].

\section{The $\lambda$-probe}

The $\lambda$-probe measures fluctuations between oxidizing and reducing conditions. It is based on an electrochemical cell made of zirconium oxide [1]. When the cell is exposed to a gas containing only oxygen and inert gases, it measures the difference between the pressures of oxygen on the reference side, $P_{\mathrm{O}_{2}}$ ref, and on the measuring side, $P_{O_{2} \text { meas. }}$. The output voltage of the cell is expressed by Nernst's equation:

$U=\frac{R T}{4 F} \ln \left(\frac{P_{O_{2} \text { ref }}}{P_{O_{2} \text { meas }}}\right)$

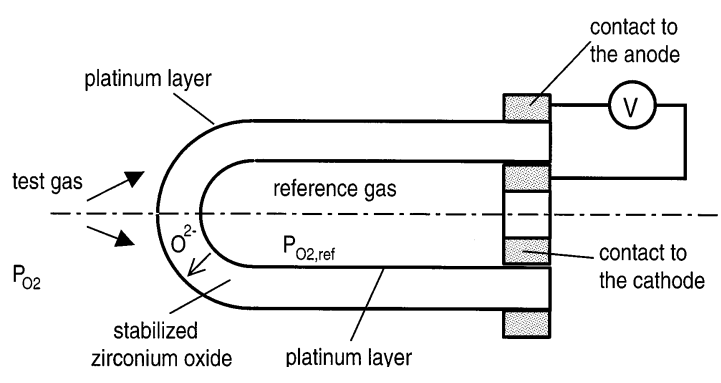

Fig. 2. A schematic drawing of the electrolyte oxygen sensor.

A schematic drawing of the cell is shown in Fig. 2. In practice the output voltage is between 0.0 and $1.0 \mathrm{~V}$. A difficulty in interpreting the signal from the cell arises if the atmosphere around the cell contains both free oxygen and combustibles like $\mathrm{CO}, \mathrm{H}_{2}$, or $\mathrm{CH}_{4}$. These gases may react with oxygen on the cell's surface, consuming the locally available oxygen. $\mathrm{CO}$ can influence the signal through another electrochemical cell, where the reaction is between $\mathrm{CO}$ and $\mathrm{O}^{2-}$. Therefore, the accurate measurement of oxygen concentrations in reacting gases is generally not possible with a $\lambda$-probe, but, instead, it is used to measure the fluctuations between oxidizing and reducing conditions detected as low and high voltages. Conditions are defined as oxidizing when the partial pressure of $\mathrm{O}_{2}$ is higher than $100 \mathrm{~Pa}$ and as reducing when it is less than $10^{-7} \mathrm{~Pa}$. These limits are chosen to be sufficiently high and low.

\section{EXPERIMENTAL}

\section{The Boiler and the Fuels}

The 12 MW CFB plant has been specially designed as a test unit for research while it is operated for commercial heat production. It is equipped with a large number of ports for the insertion of measuring probes. A detailed description is given elsewhere [8]. In the present project, measurements were made with the LIPS and $\lambda$-probes inserted through different ports so that the measuring locations were very close together. The setup is shown in Fig. 3. The square cross-section of the combustion chamber is about $2.5 \mathrm{~m}^{2}$ and the height is $13.5 \mathrm{~m}$ with the cyclone outlet beginning at $9.3 \mathrm{~m}$. Three differ- 


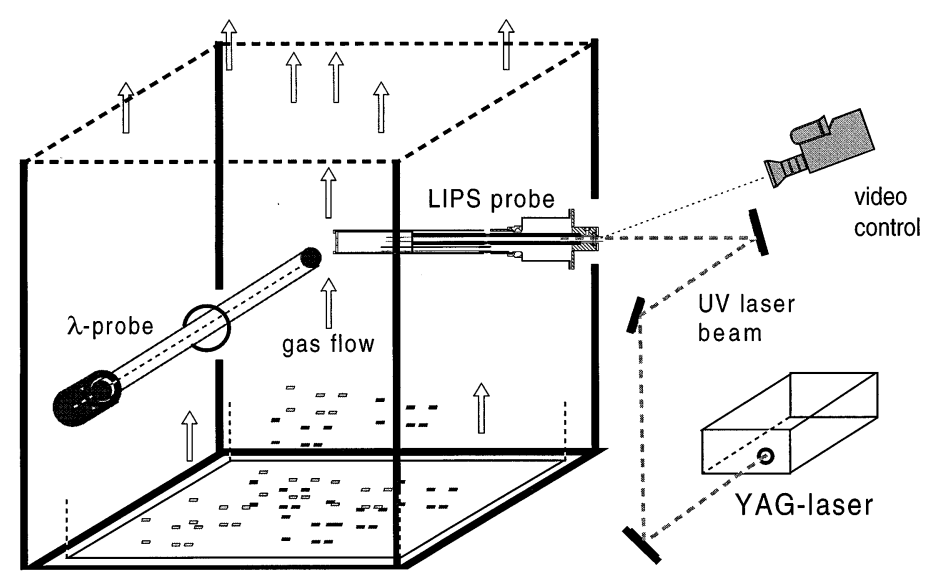

Fig. 3. Schematic setup of the LIPS and $\lambda$-probe measurement in the lower part of combustion chamber.

ent fuels were used: bituminous coal, peat, and wood chips. Their analysis in Table 1 shows that the volatile, sulfur, and nitrogen contents vary considerably between the fuels. This caused large variations in the combustion chamber of the hydrocarbon concentration, water content, and amount of nitrogen and sulfur species between the tests. The operating conditions were kept constant and the air flows to the combustor were fixed. The operating conditions are typical for a CFB-boiler: bed temperature $850^{\circ} \mathrm{C}$, a fluidization velocity of $6 \mathrm{~m} / \mathrm{s}$ and excess-air ratio of 1.2. The air supply was split into $60 \%$ primary air and $40 \%$ secondary air. The latter was

\section{TABLE 1}

Fuel Characteristics

\begin{tabular}{lccc}
\hline Type & $\begin{array}{c}\text { Wood } \\
\text { Chips }\end{array}$ & Peat & $\begin{array}{c}\text { Bituminous } \\
\text { Coal }\end{array}$ \\
\hline Volatiles, \% m.a.f. $^{a}$ & 78.0 & 69.8 & 38.8 \\
Proximate analysis, \% as delivered & & \\
$\quad$ Combustibles & 54.5 & 58.6 & 71.9 \\
Ash & 0.5 & 4.3 & 12.3 \\
Moisture & 45.0 & 37.0 & 15.8 \\
Ultimate analysis, \% & & & \\
moisture and ash & & & \\
free & 50.7 & 57.1 & 84.1 \\
$\mathrm{C}$ & 5.9 & 6.3 & 5.8 \\
$\mathrm{H}$ & 43.1 & 33.5 & 5.9 \\
$\mathrm{O}$ & 0.04 & 0.8 & 1.9 \\
$\mathrm{~S}$ & 0.2 & 2.3 & 2.2 \\
$\mathrm{~N}$ & 31 & 608 & 1113 \\
Theoretical maximum & & & \\
SO ${ }_{2}$-conc. in stack, & & & \\
ppm (wet). & & & \\
\hline
\end{tabular}

${ }^{a}$ All percentages are mass $\%$. injected into the combustor at a height of $2.2 \mathrm{~m}$. The bed material was pure silica sand and no lime for sulfur capture was supplied. The same operating conditions were maintained for all three fuels and no changes were made, except for minor adjustments of flue-gas recirculation flow (for the control of bed temperature).

\section{The Tests}

The probes were inserted into the combustion chamber through three ports located $0.56,3.7$, and $7.9 \mathrm{~m}$ above the air distributor. The lowest port is close to the dense bed, while the two others are in the transport zone. At the different heights large variations in the concentrations of $\mathrm{CO}$ and unburned hydrocarbons were measured with conventional gas analyzers. The $\lambda$-probe was inserted perpendicular to the LIPS probe, as seen in Fig. 3. The two probes were positioned inside the boiler with the probe tips only 1 to $2 \mathrm{~cm}$ from each other. While this measurement was carried out, a suction probe connected to a set of on-line gas analyzers recorded the average concentrations of several gas species in one of the other two ports.

\section{The LIPS Measurement}

The dynamic variations of the selected gases were recorded from the LIPS probe signal as a function of time for $300 \mathrm{~s}$ at fixed wavelengths. The wavelengths for $\mathrm{SO}_{2}$ and $\mathrm{NO}$ were chosen after an investigation of absorption spectra at 

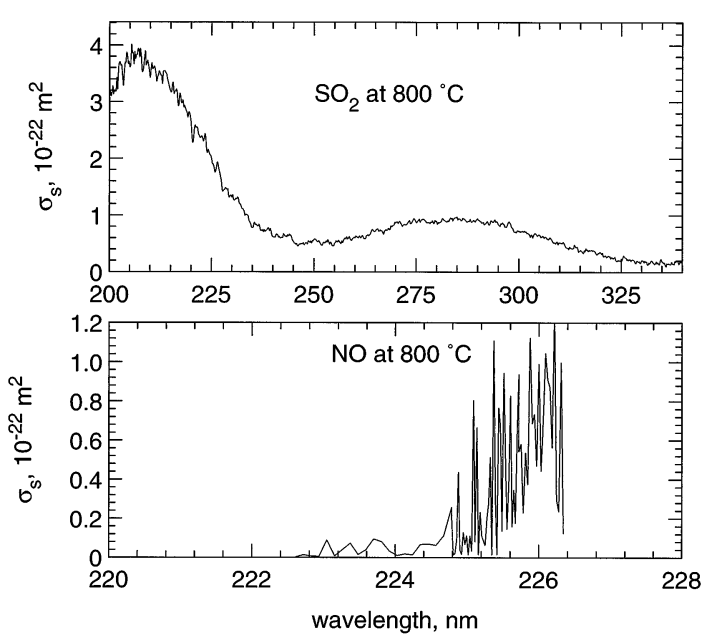

Fig. 4. Absorption spectra of $\mathrm{SO}_{2}[9]$ and $\mathrm{NO}$ at $800^{\circ} \mathrm{C}$.

fluidized bed temperatures using both LIPS with the setup described before [5] and transmission absorption spectroscopy [9]. The absorption spectra of $\mathrm{SO}_{2}$ and $\mathrm{NO}$ are shown in Fig. 4. The highest LIPS signal $\Delta P_{0}$ is obtained by maximizing the product of the wavelengthdependent, molecular cross-section $\sigma_{s}$ and the laser pulse's energy $E_{L}$, since for given conditions (temperature, pressure, and test cell geometries) all the other terms in Eq. 1 are constant. The concentration of $\mathrm{SO}_{2}$ was measured at a wavelength of $281.5 \mathrm{~nm}$ (overlapping $A^{1} A_{2}-X^{1} A_{1}$ and $B^{1} B_{1}-X^{1} A_{1}$ transitions) which coincides with maxima in both the $\mathrm{SO}_{2}$ absorption and laser pulse energy. The optimal measurement wavelength for NO was selected slightly off the strongest absorption line at $225.541 \mathrm{~nm}\left(A^{2} \Sigma^{*}-X^{2} \Pi 0,0\right.$ transition $)$ to maximize the LIPS signal. The wavelengths were fixed, but spectral interferences exist. Known spectral interferences [9] on $\mathrm{SO}_{2}$ and $\mathrm{NO}$ are given in Table 2, which shows that, e.g., 1 ppm

TABLE 2

Effect in ppm of Overlapping Molecules on the Measured Concentrations

\begin{tabular}{lccccc}
\hline $\begin{array}{l}\text { Species } \\
\text { under }\end{array}$ & $\begin{array}{c}\text { Interfering Species } \\
\text { Study }\end{array}$ & $\begin{array}{c}\mathrm{SO}_{2} \\
(\mathrm{ppm})\end{array}$ & $\begin{array}{c}\mathrm{O}_{2} \\
(\mathrm{ppm})\end{array}$ & $\begin{array}{c}\mathrm{C}_{2} \mathrm{H}_{4} \\
(\mathrm{ppm})\end{array}$ & $\begin{array}{c}\mathrm{C}_{2} \mathrm{H}_{2} \\
(\mathrm{ppm})\end{array}$ \\
\hline $\mathrm{NO}(\mathrm{ppm})$ & - & 0.25 & 0.06 & 0 & 0.15 \\
$\mathrm{SO}_{2}(\mathrm{ppm})$ & 0 & - & 0 & 0.1 & 0 \\
\hline
\end{tabular}

of $\mathrm{C}_{2} \mathrm{H}_{2}$ increases the measured concentration of NO by 0.15 ppm measured by LIPS. For the LIPS measurement of $\mathrm{SO}_{2}, \mathrm{C}_{2} \mathrm{H}_{2}$ has no influence. Since the calibration of the LIPS probe is affected by the size and position of the laser beam in the hot test cell (see Eq. 2), the LIPS probe was calibrated before each measurement by feeding a known gas mixture backwards through the LIPS probe to the measurement cell. For this purpose, the probe is equipped with a quartz tube leading from the cold part to the hot part to prevent reactions between the calibration gas and the probe material. The calibration gases contained $500 \mathrm{ppm} \mathrm{SO}_{2}$ and 500 ppm NO diluted in $\mathrm{N}_{2}$.

The prevailing acoustic noise inside the boiler was not a significant source of interference. In earlier tests the acoustic noise was reduced by passing a sufficiently high gas flow for the pressure drop over the porous filter to prevent acoustic transmission through the quartz disk. Pumping the sample gas did not reduce noise in the present case. The main source of noise during the measurements was probably not the acoustic noise in the gas, but the noise caused by the impact of solid particles on the probe tube. This impact noise was transmitted to the outside of the combustion chamber and was audible close to the probe. Mechanical insulation of the probe tube from the boiler's wall was also tested, but did not lead to a reduction of the acoustic noise. To minimize the response time of the LIPS probe, gases were pumped to the measurement cell with a flow-rate of 1.5 (coal measurements) or $2.0 \mathrm{l} / \mathrm{min}$ (other fuels). The theoretical response time of the probe is 0.39 or $0.29 \mathrm{~s}$, respectively, for the two flowrates. The measured time of the LIPS probe to reach $63 \%$ of the final reading for a step change in concentration was 0.87 or $0.77 \mathrm{~s}$ at $850^{\circ} \mathrm{C}$.

The laser system is a pulsed YAG-pumped dye laser system (Continuum YG661 and TDL60). Nonlinear crystals generate the UV light. The pulse frequency of the laser is $10 \mathrm{~Hz}$. When the wavelength is fixed in a PA measurement, 10 concentration readings/s can be made for one species. The laser system was located in a separate room below the boiler at a distance of up to $14 \mathrm{~m}$ from the probe. The direction of the laser beam into the probe affects the PA signal strongly, and a video camera system 
monitored the laser beam entrance to the probe, as shown in Fig. 3. Because mainly UV light was used, the adjustment of the laser beam was controlled by means of fluorescent paper mounted around the entrance window of the probe. The mechanical stability of the whole boiler house was good and the boiler did not move or swing too much to prevent the alignment of laser beam into the LIPS probe. The variation of the laser pulse's energy with time was measured using a silicon photodiode. The long-term laser power was stabilized manually by the laser operator. Both PA and laser pulse signals were recorded by a PC and a commercial A/D-converter electronics (DataTranslation DT2831-G). The same electronic circuit generated the synchronization pulse for $\lambda$-probe readings and monitored the laser operation.

\section{The $\lambda$-probe Measurement}

The $\lambda$-probe consists of two main parts: a long water-cooled section and an air-cooled tip. The cooling air also serves as reference air. Air was supplied at a pressure of $1.5 \mathrm{bar}$, and thus the reference partial pressure of oxygen was 0.315 bar. The oxygen sensor was a commercial device (Bosch $\mathrm{GmbH}$ ). This sensor has stainless steel and ceramic shielding layers on top of the stabilized zirconium dioxide electrolyte for protection against mechanical and chemical stresses in the combustion chamber. A minimum working temperature is required for the ceramic material of the $\lambda$-probe to conduct oxygen ions. Theoretically the minimum temperature is $300^{\circ} \mathrm{C}$, but in practice a temperature of $600^{\circ} \mathrm{C}$ is required for proper operation of the zirkonia cell [3]. This requirement was fulfilled during the measurements, but some caution had to be taken when measuring close to the watercooled walls of the combustion chamber, where the temperature may be slightly less than $600^{\circ} \mathrm{C}$. The temperature of the $\lambda$-probe was monitored by thermocouples to ensure correct operation. The $\lambda$-probe's response to fluctuations between oxidizing and reducing conditions in the CFB has been studied extensively $[2,3]$. The ratedetermining processes of the zirconia-cell are the electrode processes and gas diffusion through the boundary layer. The response time of the cell is independent of temperature, pro- vided the surface temperature of the cell is above $600^{\circ} \mathrm{C}$. This indicates that gas diffusion is dominating the response time. In the bottom bed the shifts from oxidizing to reducing conditions were faster than vice versa, which probably depends on faster diffusion of hydrogen than of oxygen. Gas concentration measurements have shown that hydrogen is present only in the bottom of the combustion chamber [10]. In all cases, the response time of the $\lambda$-probe on the centerline of the combustion chamber is shorter than that of the LIPS probe.

\section{The Sampling Probe System}

The sampling probe system consisted of a cooled suction probe connected to a set of on-line analyzers for measuring $\mathrm{O}_{2}, \mathrm{NO}, \mathrm{CO}$, $\mathrm{CO}_{2}, \mathrm{SO}_{2} \mathrm{H}_{2}$, and total hydrocarbons. In this system was also a Fourier transform infrared (FTIR) analyzer and a gas chromatograph equipped with a mass spectrometer detector (GC-MS) for analysis of individual hydrocarbons and other species such as $\mathrm{N}_{2} \mathrm{O}, \mathrm{NH}_{3}$, $\mathrm{HCN}, \mathrm{COS}$, and $\mathrm{H}_{2} \mathrm{~S}$. The suction probe has a shielded ceramic filter in order to prevent bed material from entering the gas line. The sampling probe system measures time-averaged concentrations in the combustion chamber. Further details of the system have been published $[10,11]$.

\section{RESULTS}

\section{Correlation between the LIPS and $\lambda$-probe Signal}

Figure 5 shows the concentration of $\mathrm{SO}_{2}$ and the $\lambda$-probe signal from the port $3.7 \mathrm{~m}$ above the distributor during a coal run. The $\lambda$-probe signal shows that at the measurement point both oxidizing (low $\lambda$-probe signal) and reducing conditions (high $\lambda$-probe signal) occur. Fast variations as well as longer, pulse-like periods are registered. During the longer pulses, a correlation between LIPS and $\lambda$-probe signals is obvious. An extreme case at $\sim 210 \mathrm{~s}$ in Fig. 5 in the form of a high peak of the LIPS signal is measured during a reducing period lasting $10 \mathrm{~s}$. This is seen more clearly in Fig. 6, where this 


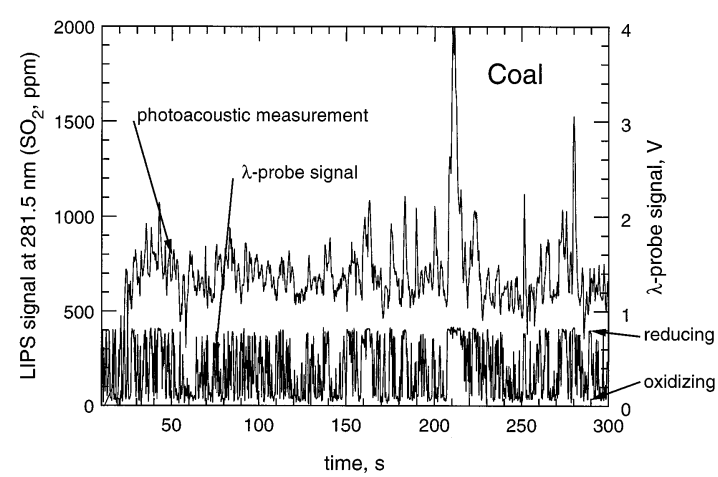

Fig. 5. LIPS signal at $281.5 \mathrm{~nm}\left(\mathrm{SO}_{2}\right)$ and $\lambda$-signal measured at $3.7 \mathrm{~m}$ with coal as fuel.

part of the measurements is expanded. Obviously, the $\mathrm{SO}_{2}$ concentration is higher during the reducing period than during the oxidizing one. This will be explained below. Long reducing periods occurred during coal combustion at $3.7 \mathrm{~m}$ and for wood chips at $0.56 \mathrm{~m}$.

An example of a measurement at $7.9 \mathrm{~m}$ is shown in Fig. 7 with peat as fuel. Because the measurements were made high up the combustor, oxidizing conditions prevail. Again, during reducing periods, a high LIPS signal is recorded. In Fig. 7 the peaks in both signals often coincide, yielding a good cross-correlation. This coincidence of signals is probably an example of an interference by hydrocarbons in the LIPS measurements. A high hydrocarbon concentration is likely during reducing periods. The degree of cross-correlation of the LIPS and $\lambda$-probe signals varies. In the measurements made at $7.9 \mathrm{~m}$ (Fig. 7), the $\lambda$-probe signals contain less variation than the measurements at

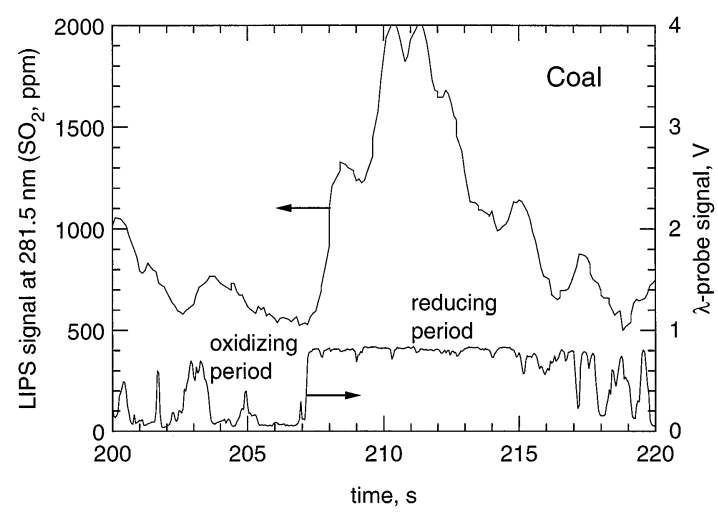

Fig. 6. Expanded view of $\mathrm{SO}_{2}$ peak at $210 \mathrm{~s}$ from Fig. 5.

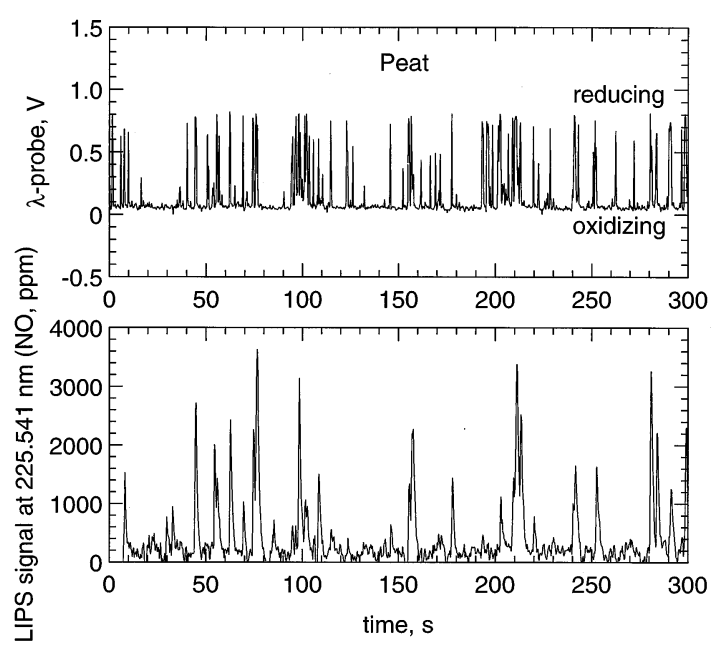

Fig. 7. LIPS and $\lambda$-probe signals at $7.9 \mathrm{~m}$ when burning peat. The LIPS signal was measured at the absorption wavelength of NO.

$3.7 \mathrm{~m}$ and especially at $0.56 \mathrm{~m}$. The less frequent peaks allow the LIPS probe to follow the events inside the combustion chamber more accurately than in the lower ports. In typical measurements at $0.56 \mathrm{~m}$ all the oxidizing and reducing periods are shorter than the response time of the LIPS probe.

Fig. 8 presents the cross-covariance function of the LIPS and $\lambda$-probe signals for the case of Fig. 7. Obviously, the two signals are crosscorrelated. The inset curve in Fig. 8 shows the peak expanded. The maximum value occurs at $0.5 \mathrm{~s}$, which is the average delay of the LIPS signal compared to the $\lambda$-signal. This is close to the difference in the response times of the two

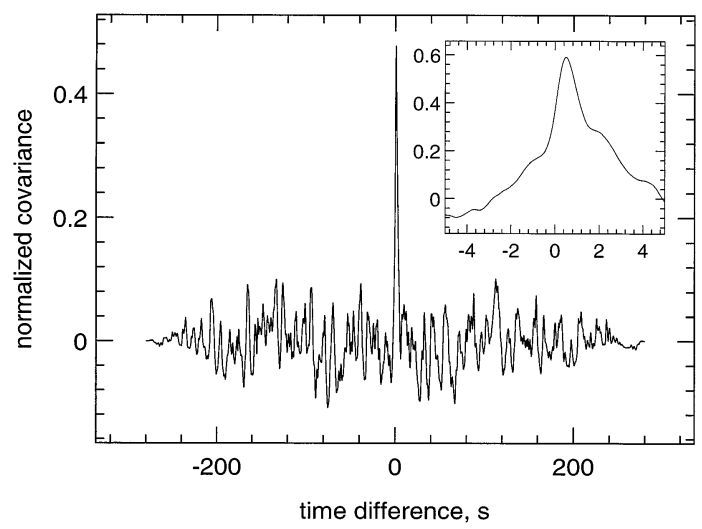

Fig. 8. Cross-covariance of the measured LIPS signal at $225.547 \mathrm{~nm}(\mathrm{NO})$ and the $\lambda$-probe signals in Fig. 7. 
TABLE 3

Average Gas Concentrations Measured with LIPS and the On-line Instruments for $\mathrm{NO}$ and $\mathrm{SO}_{2}$

\begin{tabular}{|c|c|c|c|c|c|c|}
\hline & \multicolumn{3}{|c|}{$\mathrm{NO}(\mathrm{ppm})$} & \multicolumn{3}{|c|}{$\mathrm{SO}_{2}(\mathrm{ppm})$} \\
\hline & Coal & Wood & Peat & Coal & Wood & Peat \\
\hline \multicolumn{7}{|l|}{$0.56 \mathrm{~m}$} \\
\hline LIPS & 2513 & 6744 & 4717 & 3909 & 5008 & 2533 \\
\hline On-line analyzer & 570 & 141 & 293 & 1400 & 277 & 410 \\
\hline \multicolumn{7}{|l|}{$3.7 \mathrm{~m}$} \\
\hline LIPS & 594 & 3032 & 535 & 695 & 378 & 442 \\
\hline On-line analyzer & 209 & 195 & 101 & 1312 & 49 & 386 \\
\hline \multicolumn{7}{|l|}{$7.9 \mathrm{~m}$} \\
\hline LIPS & 471 & 240 & 383 & 810 & 31.6 & 433 \\
\hline On-line analyzer & 147 & 159 & 131 & 1180 & 59 & 396 \\
\hline
\end{tabular}

probes. The cross-correlation function is affected by the different characteristics of the two signals. In addition to different response times, the $\lambda$-signal is a digital-like signal and is stable only at low or high values in contrast to the continuous LIPS signal.

\section{Comparison between LIPS and Suction Probe Measurements}

The concentrations of gases were measured by the sampling probe system in parallel with the LIPS system. The average concentrations of $\mathrm{SO}_{2}$ and $\mathrm{NO}$ measured with LIPS and the on-line analyzers for $\mathrm{NO}$ and $\mathrm{SO}_{2}$ are compared in Table 3. Large differences in the measured values of gas concentrations are observed. In measurements close to the bed's surface at $0.56 \mathrm{~m}$, the LIPS readings are much higher than those from the suction probe. The difference between the two sets of data decreases significantly from $0.56 \mathrm{~m}$ to $7.9 \mathrm{~m}$. The source of interference is probably large hydrocarbon molecules active at the wavelength of the LIPS measurement and present in high concentrations close to the bottom of the bed. These molecules can occasionally reach the upper parts of the combustion chamber in plumes and the NO concentrations measured with LIPS are higher than those from the suction probe, due to spectral interference by other molecules as seen in Fig. 7.

The effect of interference by hydrocarbon molecules on LIPS signals can be minimized by sorting out the LIPS signals using the informa-
TABLE 4

Sorted LIPS Measurements

\begin{tabular}{|c|c|c|c|c|c|c|}
\hline & \multicolumn{3}{|c|}{ NO (ppm) } & \multicolumn{3}{|c|}{$\mathrm{SO}_{2}(\mathrm{ppm})$} \\
\hline & Coal & Wood & Peat & Coal & Wood & Peat \\
\hline \multicolumn{7}{|l|}{$0.56 \mathrm{~m}$} \\
\hline LIPS & N/A & N/A & N/A & N/A & 2412 & N/A \\
\hline On-line analyzer & 570 & 141 & 293 & 1400 & 277 & 410 \\
\hline \multicolumn{7}{|c|}{$3.7 \mathrm{~m}$} \\
\hline LIPS & 280 & 390 & 154 & 604 & 45 & 220 \\
\hline On-line analyzer & 204 & 195 & 101 & 1312 & 49 & 386 \\
\hline \multicolumn{7}{|c|}{$7.9 \mathrm{~m}$} \\
\hline LIPS & 379 & 107 & 182 & 768 & N/A & 244 \\
\hline On-line analyzer & 147 & 159 & 131 & 1180 & 59 & 396 \\
\hline
\end{tabular}

tion available in the synchronous $\lambda$-probe signals. Table 4 shows the sorted LIPS concentrations measured during sufficiently long oxidizing periods, when the hydrocarbon concentration is at minimum. The length of the oxidizing periods selected was longer than the calibrated response time of the LIPS probe, i.e., $0.87 \mathrm{~s}$ with coal and $0.78 \mathrm{~s}$ for wood or peat. After sorting out these reducing periods, the agreement between the LIPS and the suction probe measurement improved considerably. Sometimes, the variations in the process measured by the $\lambda$-probe were too fast for the LIPS probe to follow. When all of the oxidizing periods in the measurement were too short, no sorting could be done, as indicated by N/A (not available) in Table 4. Sorting LIPS signals into reducing and oxidizing periods has a large impact on the measured NO concentration. This may depend directly or indirectly on the local oxygen concentration, but it is obvious that the NO measurement has been affected by spectral interference from other species. The LIPS measurement of $\mathrm{SO}_{2}$ is less affected by other molecules as a consequence of its absorption wavelength.

\section{Measurement of the $\mathrm{OH}$ Radical}

The LIPS measurement of the $\mathrm{OH}$ radical spectrum in the boiler was also tested. The free radical $\mathrm{OH}$ has an absorption band at $283 \mathrm{~nm}$, caused by the $A^{2} \Sigma^{+}-X^{2} \Pi(1,0)$ transition. This is normally overlapped by the $\mathrm{SO}_{2}$ absorption band. Owing to the low sulfur content of wood chips, the $\mathrm{SO}_{2}$ concentration was low during the 


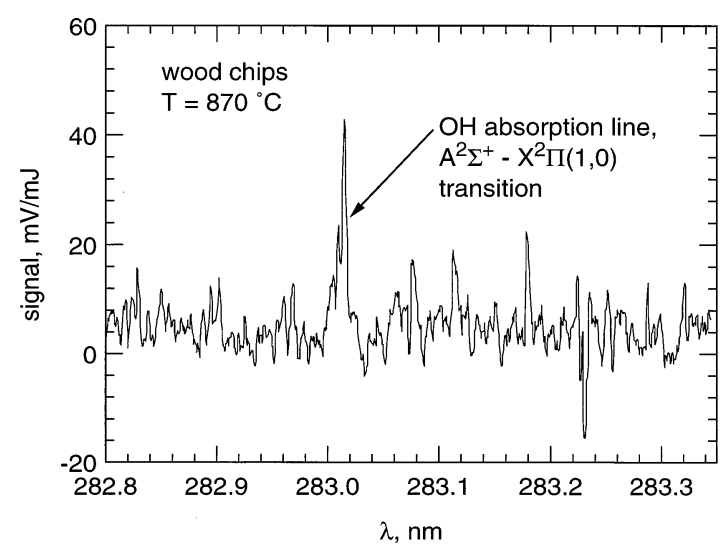

Fig. 9. $\mathrm{OH}$ absorption line measured at $7.9 \mathrm{~m}$ when burning wood chips.

run with wood chips. A slow wavelength scan was performed in order to filter out time variations in the LIPS signal and one $\mathrm{OH}$ absorption line could be measured at $7.9 \mathrm{~m}$ (see Fig. 9). Because the measurement location was high above the bottom bed, in a low-reactivity zone, the concentration of $\mathrm{OH}$ is probably close to equilibrium at $870^{\circ} \mathrm{C}$ which was the temperature in the combustion chamber at $7.9 \mathrm{~m}$ during the wood chips run. This is similar to LIPS calibrations of $\mathrm{OH}$ in the laboratory, where the equilibrium condition was attained by thermal decomposition of water vapor in a furnace $[12,13]$.

\section{DISCUSSION}

A clear correlation between the LIPS and $\lambda$-probe signals was found in regions above the bottom bed. This confirms the ability of the LIPS probe to capture the dynamic behavior of the CFB combustor. Recognizing the interference by hydrocarbons, the origin of the correlation may be different for $\mathrm{SO}_{2}$ and NO. If a plume of hydrocarbon $(\mathrm{HC})$ reaches the two probes, a reducing condition is noted by the $\lambda$-probe, and the UV absorption of the HC compounds gives a high LIPS reading in the NO measurement. In the case of $\mathrm{SO}_{2}$, other phenomena can also occur. High peaks of $\left[\mathrm{SO}_{2}\right]$ were found with coal, although the average $\mathrm{SO}_{2}$ concentration measured by LIPS was not higher than measured by the on-line analyzers. In the case of coal, a plume of burning volatiles can generate reducing conditions and yet can con- tain a high concentration of $\mathrm{SO}_{2}$ despite the reducing conditions.

The ability to measure fluctuations in gas concentrations in particle-laden combustion gases by LIPS is proven. On the other hand, the possibility of measuring the concentrations accurately is restricted. In most cases the average concentrations measured by LIPS were higher than the corresponding on-line analyzers connected to the suction probe as shown by Table 3 . The most probable reason for this is spectral interference from other molecules, but the source of the interference is not known precisely. The concentrations of many hydrocarbon compounds were measured by FTIR. The dominant hydrocarbon is $\mathrm{CH}_{4}$, which does not interfere in LIPS at all. Both $\mathrm{C}_{2} \mathrm{H}_{4}$ and $\mathrm{C}_{2} \mathrm{H}_{2}$ are known to interfere with LIPS measurement of NO, but the concentrations of these species are not sufficient to cause the high LIPS readings observed. In the lower parts of the boiler, high concentrations of aromatic compounds, such as benzene and toluene $\left(\mathrm{C}_{7} \mathrm{H}_{8}\right)$, were found by the GC-MS. The peaks of the ro-vibronic absorption bands of $\mathrm{C}_{6} \mathrm{H}_{6}$ and $\mathrm{C}_{7} \mathrm{H}_{8}$ relevant to this work are at $254 \mathrm{~nm}\left(\mathrm{C}_{6} \mathrm{H}_{6} \alpha\right.$-band $), 204 \mathrm{~nm}$ ( $\mathrm{C}_{6} \mathrm{H}_{6}$ p-band), $262 \mathrm{~nm}\left(\mathrm{C}_{7} \mathrm{H}_{8} \alpha\right.$-band $)$, and 208 $\mathrm{nm}\left(\mathrm{C}_{7} \mathrm{H}_{8}\right.$ p-band $)$ at room temperature [14, 15]. At $850^{\circ} \mathrm{C}$ the vibrationally excited (hot) p-bands at $225.5 \mathrm{~nm}$ may be populated up to $1 \%$ compared to the vibrational ground state. The high absorption cross-sections of these molecules can cause significant interference in the measurement of [NO] with LIPS. The hot absorption band intensities of $\mathrm{C}_{6} \mathrm{H}_{6}$ and $\mathrm{C}_{7} \mathrm{H}_{8}$ at $281.5 \mathrm{~nm}$ ( $\alpha$-bands) at $850^{\circ} \mathrm{C}$ are probably a few percent compared to the absorption peaks. Since the $\alpha$-bands are not very intense, significant interference with $\left[\mathrm{SO}_{2}\right]$ measurements is expected when the concentrations of the aromatic compounds exceed the $\mathrm{SO}_{2}$ concentration by an order of magnitude. The question arises whether the present LIPS system can be modified in order to improve the measurements of accurate levels of $\mathrm{NO}$ and $\mathrm{SO}_{2}$ in a combustion environment. This would need the simultaneous measurement on dual wavelengths (at both the absorption peak and at reference level) and a better knowledge of which hydrocarbons are present, their concentrations and absorption characteristics within the spectral range of in- 
terest, obtained by extensive calibrations in a laboratory at temperatures of $800-900^{\circ} \mathrm{C}$.

\section{CONCLUSIONS}

Previous measurements in flue gases have shown that the LIPS probe, measuring in the UV and near-visible spectral region, has advantages compared with devices working in the IR, but these advantages are no longer obvious for measurements in burning gases, where the activity of large hydrocarbon molecules cover significant spectral regions. In combustion chambers, however, measurements are possible of $[\mathrm{NO}]$ and $\left[\mathrm{SO}_{2}\right]$ in large pockets of gas, where an excess of oxygen has reduced the concentration of disturbing gases. The measurement of other interesting species absorbing in the UV, like $\mathrm{NH}_{3}$ and $\mathrm{H}_{2} \mathrm{~S}$ is also possible, at least in principle. These two molecules have lower absorption cross-sections than, for example, NO and this decreases the signal-to-noise ratio and makes the measurement even more prone to interference in burning gases. On the other hand, the spectral region between 220-280 nm allows the measurement of some aromatic compounds, especially with dual wavelength system after calibrations with known concentrations at temperatures between $800-900^{\circ} \mathrm{C}$. Some interesting molecules like $\mathrm{HCN}$ still have to be measured optically in the IR, due to a lack of a suitable UV absorption band. The response time of the LIPS was longer than that of the zirconia-cell probe, but sufficiently short to capture the principal variations of the gas concentrations in the fluidized bed. The instrument investigated could be used in the industrial environment of a boiler and its surroundings without severe acoustic disturbances. The predominant external acoustic influence originated probably from the fluidized particles impinging on the probe.
This work was supported financially by the Finnish National Combustion and Gasification Research Program (LIEKKI) and by the Swedish National and Technical Board for Industrial Development (NUTEK).

\section{REFERENCES}

1. Minchener, A. J., and Stringer, J., J. Inst. Energy 37:240-251 (1984).

2. Lyngfelt, A., Bergqvist, K., Johnsson, F., Åmand, L-E., and Leckner, B., in Gas Cleaning at High Temperatures (R. Clift, and J. P. K. Seville, Eds.), Blackie Academic \& Professional, Glasgow, 1993, pp. 470-491.

3. Bergqvist, K., Thesis for the Degree of Licentiate of Engineering, Chalmers University of Technology, Göteborg, Sweden, 1995.

4. Stenberg, J., and Hernberg, R., Joint Meeting of the British and German Sections, The Combustion Institute, Cambridge, 1993, pp. 259-262.

5. Stenberg, J., Hernberg, R., and Vattulainen, J., Appl. Opt. 34:8400-8408 (1995).

6. Zharov, V. P., and Letokhov, V. P., Laser Optoacoustic Spectroscopy, Springer-Verlag, Heidelberg, 1986, pp. $16-44$.

7. Brassington, J., J. Phys. D: Appl. Phys. 15:219-228 (1982).

8. Åmand, L-E., and Leckner, B., Energy Fuels 7:10971107 (1993).

9. Vattulainen, J., Stenberg, J., Wallenius, L., Hernberg, R., and Linna, V., in Appl. Spectros, 51:1311-1314.

10. Åmand, L-E., and Leckner, B. (1994). Report A 94-209. Dept. of Energy Conversion, Chalmers University of Technology.

11. Åmand, L-E., and Tullin, C., The Nordic Seminar on Gas Analysis in Combustion, Tampere University of Technology, Finland, 1994, pp. 42-52.

12. Quagliaroli, T. M., Laufer, G., and McDaniel, J. C., Appl. Phys. B 59:635-638 (1994).

13. Grinstead, J. H., Laufer, G., Krauss, R. H., and McDaniel, J. C. Jr., Appl. Opt. 33:1115-1119 (1994).

14. Birks, J. B., Photophysics of Aromatic Molecules, WileyInterscience, London, 1972, p. 70.

15. Harris, D. C., and Bertolucci, M. D., Symmetry and Spectroscopy, Oxford University Press, New York, 1978, p. 388.

Received 3 May 1996; accepted 14 July 1997 